\title{
Associations between stress, fatigue, sleep disturbances and dental students' oral health-related behaviours: Changes throughout academic year
}

\section{Związki między stresem, zmęczeniem i zaburzeniami snu a zachowaniami dotyczącymi zdrowia jamy ustnej u studentów stomatologii - zmiany w ciągu roku akademickiego}

\author{
Adomas Rovas ${ }^{A-F}$, Agnè Staniulytè ${ }^{A-F}$, Alina Püriené $\dot{A}^{A, E, F}$ \\ Institute of Odontology, Faculty of Medicine, Vilnius University, Vilnius, Lithuania \\ A - research concept and design; $\mathrm{B}$ - collection and/or assembly of data; $\mathrm{C}$ - data analysis and interpretation; \\ $D$ - writing the article; $E$ - critical revision of the article; $F$ - final approval of article
}

Address for correspondence

Adomas Rovas

E-mail: adomasrovas@gmail.com

Funding sources

none declared

Conflict of interest

none declared

Received on December 13, 2016

Revised on January 19, 2017

Accepted on March 2, 2017

\begin{abstract}
Background. Stress, fatigue and sleep disturbances are common among university students and they have an impact on their personal health. The prevalence as well as the influence of these factors on oral health-related behaviors are likely to vary during the academic year.
\end{abstract}

Objectives. The objective of this study was to evaluate the prevalence of symptoms related to stress, fatigue and sleep disturbances among dental students during the academic year and to investigate whether these symptoms are associated with oral health-related behaviors.

Material and methods. The prospective study surveyed dental students from Vilnius University, Institute of Odontology at the beginning of the academic year (September) and during the examination period (December). The questionnaire given was individually coded and consisted of Fatigue Assessment Scale, Karolinska Sleep Questionnaire, Reeder Stress Assessment Scale and questions assessing self-reported oral health-related behaviors. Out of 121 dental students, 92 students completed the questionnaire both times and were included in the study (dropout rate $-8.9 \%$, response rate $-76 \%$ ).

Results. Correlations were found among disturbed sleep, insufficient amount of sleep, poor sleep quality and several oral health-related variables: tooth brushing frequency, flossing frequency, the use of a single-tuft toothbrush and a tongue cleaner $(p<0.05)$. Compared to the beginning of the academic year, a significant increase in the number of students suffering from difficulties waking up in the morning (from 52 (56.5\%) to $63(68.5 \%), p=0.027$ ), daytime sleepiness (from $19(20.7 \%)$ to $34(37 \%), p=0.008$ ), sleep quality disorders (from $9(9.8 \%)$ to $25(27.2 \%), p=0.002$ ) as well as perceiving fatigue (from $22(23.9 \%)$ to $48(52.2 \%)$, $p<0.001$ ) and stress (from $31(33.7 \%)$ to 54 (58.7\%), $p<0.001$ ) was observed during the examination period. Increased prevalence of these factors was related with insufficient oral health-related behavior.

DOI

$10.17219 / \mathrm{dmp} / 68782$

Copyright

(C) 2017 by Wroclaw Medical University

and Polish Dental Society

This is an article distributed under the terms of the

Creative Commons Attribution Non-Commercial License

(http://creativecommons.org/licenses/by-nc-nd/4.0/)
Conclusions. This study revealed that oral health-related behaviors worsen when there is a higher prevalence of stress, fatigue and sleep disturbances.

Key words: fatigue, dental students, sleep disorders, psychological stress, oral hygiene

Słowa kluczowe: zmęczenie, studenci stomatologii, zaburzenia snu, stres psychiczny, higiena jamy ustnej 
Oral health is strongly affected by oral health-related behaviors. Proper individual oral hygiene is necessary in order to avoid various oral diseases, such as caries, gingivitis, periodontitis, etc. Various individual and environmental factors may have an impact on oral health-related behaviors. Studies suggest that individual oral hygiene correlates with emotions, physical and mental state. ${ }^{1,2}$ A positive corelation was revealed between the sense of humor, self-esteem, self-confidence, self-love and the frequency of oral hygiene appliances usage. ${ }^{1-3}$ Moreover, behavioral activity and fatigue were related to appropriate and infrequent oral health-related behaviors respectively. ${ }^{4}$ Previous studies have shown that knowledge about the etiology of oral diseases as well as an understanding the necessity of maintaining good oral hygiene is an encouragement towards proper oral health-related behaviors and correlates with better oral health status., Consequently, a number of studies have been carried out to evaluate the oral health of dental students and oral health-related behaviors. Though dental students are constantly educated on preventive dentistry, results indicate that students' oral health improves only after entering clinical training and might deteriorate until graduation. ${ }^{6}$ It was shown that an average senior student's oral health was fairly good; however, a number of students with very poor oral hygiene were recorded as well. ${ }^{6}$ In an attempt to explain this phenomenon, it is important to consider the fact that the dental study program is one of the most intense study programs requiring an ability to memorize a lot of information as well as the ability to handle emotional stress related to clinical experience. Individual capability to handle these environmental challenges results in different levels of perceived stress, fatigue or sleep disorders and is likely to influence oral health-related behavior.

Some amount of stress might be desirable in order to prevent under-stimulation; however, long-term stress may cause insomnia, depression, substance misuse and decreased learning efficiency. ${ }^{7}$ Chronic stress is quite common amongst university students, especially amongst dental students. It is known that examination and a fear of underperforming as well as limited time for relaxation appear to be the most stressful elements for dental students. $^{8}$

Eventually, high levels of stress during the daytime may lead to sleep disturbances. Sleep and sleeplessness-related problems are a relevant issue in modern society as the prevalence of insomnia-related symptoms among adults is approximately 30\%. ${ }^{9}$ Inadequate duration and quality of sleep is associated with various somatic and psychiatric disorders. These disorders include such serious conditions as depression, anxiety, substance abuse and cardiovascular disease. ${ }^{10}$ The most notable risk factors for insomnia are: female sex, low levels of physical activity and high levels of perceived stress. ${ }^{11}$ Consequently, both sleep disturbances and stress may lead to fatigue, which is a major component of the Burnout syndrome and chronic fatigue syndrome. ${ }^{12,13}$

It is possible that stress, fatigue or sleep disturbance might interfere with dental students' daily oral healthrelated behavior. Even though similar assumptions were examined in previous studies, no study has investigated how levels of stress, fatigue and sleep disturbances change from the beginning of the academic year until the examination period and how it might relate to varying oral health-related behaviors.

The primary aim of this study was to examine the associations between oral health-related behaviors and symptoms of stress, fatigue and sleep disorders. Additional aims of the study include investigating the prevalence of stress, fatigue and sleep disturbances and evaluate changes during academic year.

\section{Material and methods}

This study has been conducted in full accordance with World Medical Association Declaration of Helsinki. A questionnaire was given to all dental undergraduate students at Vilnius University, Institute of Odontology, along with an explanation of the study purpose. Written consent was obtained from all participants who agreed to participate in the study. A self-administered questionnaire was given 2 times: at the beginning of the academic year (in September) and during the examination period (in December). The questionnaire was individually coded for matching purposes. The code did not include personal details; therefore, all participants remained anonymous. In September, 101 out of 121 dental students participated in the study. Students, who filled in the questionnaire in September, were asked to repeat the questionnaire in December. A total of 92 students, who completed the questionnaire both times, were selected for the study (response rate $=76 \%$, dropout rate $=8.9 \%$ ).

The questionnaire consisted of 4 different sections: questions assessing oral health-related behavior, Fatigue Assessment Scale (FAS) ${ }^{14}$, Karolinska Sleep Questionnaire $(\mathrm{KSQ})^{15}$ and Reeder Stress Assessment Scale (RSAS). ${ }^{16}$ Demographic information was collected regarding gender, age and the year of undergraduate studies. Questions, which examined oral health-related behavior, were designed by the authors and took into consideration previously performed research on similar topics. ${ }^{1-3}$ These questions included the frequency of tooth brushing, flossing, mouth rinsing, etc. The 10-question Fatigue Assessment Scale was used to investigate symptoms of fatigue. FAS was originally designed to reveal physical and mental fatigue, yet the scale might also be used as a onedimensional questionnaire when a total score of FAS is measured. ${ }^{17}$ Each item is scored on a 5-point Likert scale with the total score ranging from 10 to 50 . In the present study FAS score was dichotomized and scores $\geq 22$ were 
considered as indication of fatigue. ${ }^{18}$ The scale's validity and reliability of FAS were good. ${ }^{18}$ Karolinska Sleep Questionnaire was used to reveal symptoms of difficulties waking up in the morning, daytime sleepiness and sleep quality disorders. Other questions assessed the participants' opinion on their sleep quality, amount of sleep, nap frequency, etc. Reeder Stress Assessment Scale was used to investigate symptoms of stress. This one-dimensional questionnaire was grouped according to instructions, regarding total score: $21-28$ - no symptoms of stress or nervousness, 15-20 - symptoms of nervous strain, 7-14 - symptoms of stress. ${ }^{19} \mathrm{KSQ}$ and FAS were translated in Lithuanian using back translation methods. A measured Cronbach's alpha for the Lithuanian version of FAS and various subscales of KSQ was good, with the score ranging from 0.771 to 0.936 . Reeder Stress Assessment Scale was translated into Lithuanian language and adapted by Gostautas in 1972. ${ }^{19}$ The scale's Cronbach's alpha is good as well $(\alpha=0.75)$.

Descriptive statistics and statistical analyses were performed using statistical software (SPSS v. 21.0). Results are shown for all 92 participants included in the study and are grouped by sex and undergraduate study year. The internal consistency of FAS, KSQ and RSAS was examined using Cronbach's alpha. Fisher's exact test was used to investigate categorical variables. To assess related samples' changes of categorical variables Wilcoxon signed-rank test was used. Other tests used in the study were Binary logistic regression and McNemara test. P-values lower than 0.05 were considered to be statistically significant.

\section{Results}

Out of 92 dental students, 69 (75\%) were female and 23 (25\%) were male. Mean age of participants was 20.72 $(\mathrm{SD}=1.59)$ years. Participants' distribution among study years was similar, ranging from 16 to 20 students per undergraduate study year. More than $97 \%$ of all dental students brushed their teeth at least once a day in September as well as in December. The use of other oral hygiene appliances is revealed in Fig. 1. Considering prevalence of symptoms of stress, increased fatigue and sleep disturbances were observed in December compared to data collected in September (Fig. 2). McNemara test revealed that the increase of mentioned symptoms was significant (the significance level is represented in Fig. 2). In September significant differences were found in levels of stress according to gender and study year: female compared to male $(\mathrm{p}=0.041)$ and first-year dental students compared to other students $(\mathrm{p}=0.007)$ perceived higher levels of stress (Fig. 3). Moreover, first-year dental students were more fatigued than others at the beginning of the academic year $(p=0.034)$. In December first-year dental students were neither more stressed nor more fatigued than other students $(\mathrm{p}>0.05)$ while the levels of stress among

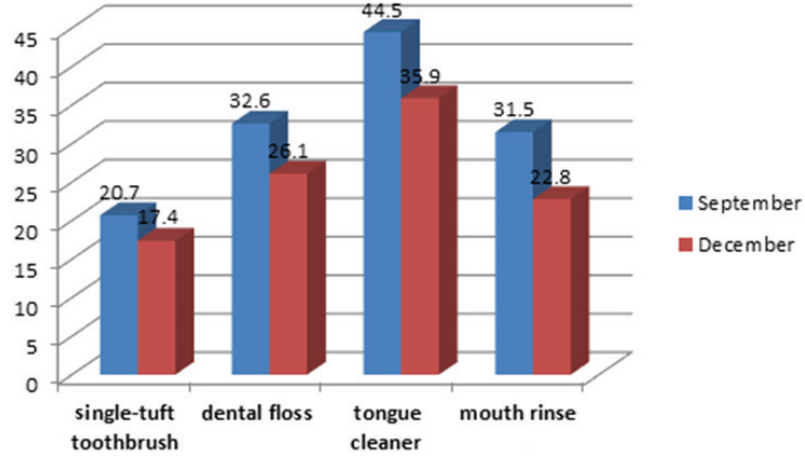

Fig. 1. Percentage of students who used various oral hygiene products at least once a day

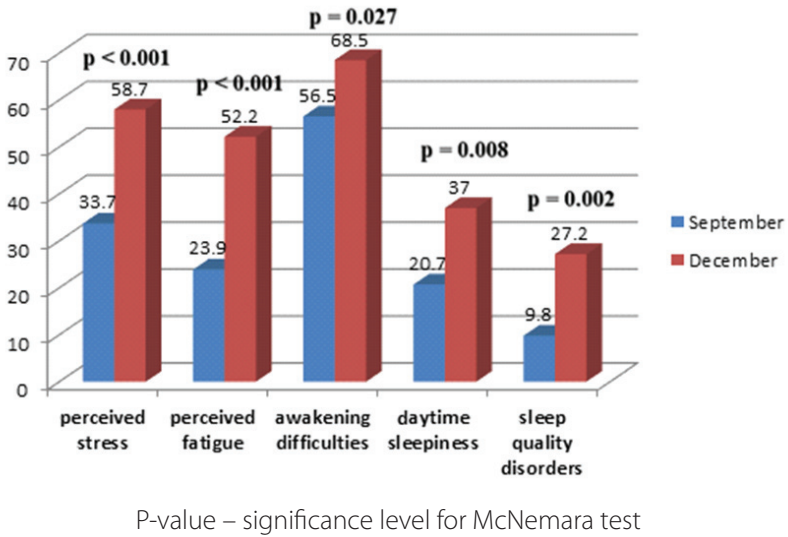

Fig. 2. Percentage of students with symptoms of stress, fatigue and sleep disorders

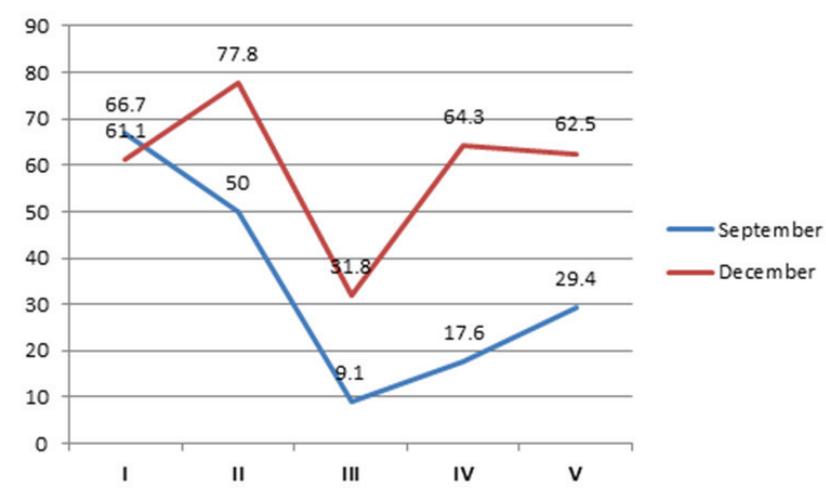

Fig. 3. Percentage of students with symptoms of stress according to the year of study

female dental students compared to male students were even more significant $(\mathrm{p}<0.001)$. No other significant differences among gender or study year were revealed in oral health-related behaviours or the prevalence of stress, fatigue and sleep disorders.

The matched coding applied in the present study allowed for the analysis of data based on the individual lev- 
el. Wilcoxon signed-rank test revealed that the prevalence of sleep quality disorders, daytime sleepiness, difficulties waking up in the morning as well as symptoms of fatigue and stress increased significantly in December compared to September (Table 1). Oral health-related behavior was also worse in December, as shown in Fig. 1, based on population level data; however, on the individual level data, only the usage of mouth rinse declined significantly $(\mathrm{p}=0.008)$.

Significant associations were found between sleep disorders, symptoms of fatigue and oral health-related behavior. In September participants who rated their overall amount of sleep as being sufficient were more likely to use a tongue cleaner compared to those who rated their amount of sleep as being insufficient ( $p=0.008)$. Moreover, students who preferred to take naps regularly used dental floss less often compared to other dental students ( $\mathrm{p}=0.044)$. In December dental students' negative opinion towards their sleep quality was associated with the use of a toothbrush: $40.7 \%$ of the students who rated their sleep quality as being poor and $12.3 \%$ who claimed to sleep well used toothbrush only once a day or less frequently $(p=0.041)$. Moreover, the risk of using a toothbrush once a day or less was 11 fold higher in students suffering from sleep quality disorders $(\mathrm{p}<0.001)$. No other associations between various sleep disorders and oral health-related behaviors were revealed. The present study revealed that symptoms of fatigue had a significant influence on oral health-related habits: fatigued dental students had a multiple times higher risk of neglecting the usage of various oral hygiene appliances (Table 2). Binary logistic regression test did not reveal significant associations between symptoms of stress and oral hygiene habits.

\section{Discussion}

To the best of our knowledge, this study was the first attempt to assess changes in oral health-related behavior taking into account the levels of sleep disturbances, fatigue and stress increase among dental students in Lithuania. The longitudinal design of the study might add to the understanding of stress, fatigue and sleep disturbances associations with oral health-related behaviors.

At the beginning of the academic year dental students presented fewer symptoms of stress, fatigue and sleep disorders compared to December when the examination period began. Symptoms of insomnia, fatigue and perceived stress increased 2.8 times, 2.2 times and 1.7 times respectively. Stress, fatigue and sleep disturbances are closely related to each other and might be induced by various individual as well as environmental risk factors. Despite numerous possible reasons, increased workload during the examination period is seen as the most common and, therefore, the most important reason for the increase of fatigue, stress and sleep disturbances in the present study. This data is supported by other research reporting that a heavy workload is related to impaired sleep, increased fatigue and higher levels of stress. ${ }^{11}$ Not only is the increase of symptoms during examination evident on population level data, but also significant on individual level data according to Wilcoxon signed-rank test. It is important to point out that even though the number of students with symptoms of stress largely increased in December, the base score in September was also high at $33.7 \%$. The overall percentage of dental students perceiving stress in September was raised by first year dental students, with $2 / 3$ of freshman year participants experienc-

Table 1. The change in the prevalence of symptoms of stress, fatigue and sleep disturbances in December compared to September (negative ranks represent increased prevalence of symptoms)

\begin{tabular}{|c|c|c|c|c|c|c|}
\hline Variables & Signed ranks & $\mathrm{N}$ & Mean rank & Sum of ranks & Z-value & P-value \\
\hline $\begin{array}{l}\text { Sleep quality } \\
\text { disorders }\end{array}$ & $\begin{array}{c}\text { negative } \\
\text { positive } \\
\text { ties } \\
\text { total }\end{array}$ & $\begin{array}{c}20 \\
4 \\
68 \\
92\end{array}$ & $\begin{array}{l}12.50 \\
12.50\end{array}$ & $\begin{array}{c}250.00 \\
50.00\end{array}$ & -3.266 & 0.001 \\
\hline $\begin{array}{l}\text { Awakening } \\
\text { difficulties }\end{array}$ & $\begin{array}{c}\text { negative } \\
\text { positive } \\
\text { ties } \\
\text { total }\end{array}$ & $\begin{array}{c}16 \\
5 \\
71 \\
92\end{array}$ & $\begin{array}{l}11.00 \\
11.00\end{array}$ & $\begin{array}{c}176.00 \\
55.00\end{array}$ & -2.400 & 0.016 \\
\hline $\begin{array}{l}\text { Daytime } \\
\text { sleepiness }\end{array}$ & $\begin{array}{c}\text { negative } \\
\text { positive } \\
\text { ties } \\
\text { total }\end{array}$ & $\begin{array}{c}22 \\
7 \\
63 \\
92\end{array}$ & $\begin{array}{l}15.00 \\
15.00\end{array}$ & $\begin{array}{l}330.00 \\
105.00\end{array}$ & -2.785 & 0.005 \\
\hline $\begin{array}{l}\text { Symptoms } \\
\text { of fatigue }\end{array}$ & $\begin{array}{c}\text { negative } \\
\text { positive } \\
\text { ties } \\
\text { total }\end{array}$ & $\begin{array}{c}28 \\
2 \\
62 \\
92\end{array}$ & $\begin{array}{l}15.50 \\
15.50\end{array}$ & $\begin{array}{c}434.00 \\
31.00\end{array}$ & -4.747 & 0.000 \\
\hline Stress & $\begin{array}{l}\text { negative } \\
\text { positive } \\
\text { ties } \\
\text { total }\end{array}$ & $\begin{array}{c}36 \\
7 \\
49 \\
92\end{array}$ & $\begin{array}{l}22.88 \\
17.50\end{array}$ & $\begin{array}{l}823.50 \\
122.50\end{array}$ & -4.515 & 0.000 \\
\hline
\end{tabular}

P-value - significance level for paired samples, Wilcoxon signed-rank test. 
Table 2. The risk of inappropriate oral health-related behaviours depending on symptoms of fatigue

\begin{tabular}{|c|c|c|c|c|c|c|c|c|c|}
\hline & \multicolumn{3}{|c|}{$\begin{array}{l}\text { Risk of using a toothbrush } \\
\text { once a day or less } \\
\end{array}$} & \multicolumn{3}{|c|}{$\begin{array}{l}\text { Risk of using a single tuft toothbrush } \\
\text { once a day or less }\end{array}$} & \multicolumn{3}{|c|}{$\begin{array}{l}\text { Risk of using a tongue cleaner } \\
\text { once a day or less }\end{array}$} \\
\hline & OR & $95 \% \mathrm{Cl}$ & $p$-value & OR & $95 \% \mathrm{Cl}$ & $p$-value & OR & $95 \% \mathrm{Cl}$ & $\mathrm{p}$-value \\
\hline Symptoms of fatigue & 6.83 & $1.83-25.5$ & 0.004 & 10.44 & $1.25-87.34$ & 0.03 & 4.13 & $1.22-14.0$ & 0.023 \\
\hline
\end{tabular}

P-value - significance level for Binary logistic regression

ing symptoms of stress at that time. It might be the result of leaving parents' home and starting university. A period of adaptation to the new environment among first year dental and medical students is a known stress factor. ${ }^{20}$ Moreover, the assumption is supported by the fact that first year dental students are the only ones whose levels of stress decreased in December. Even though distribution of symptoms of stress, fatigue and sleep quality disorders was different according to study year and gender, no significant differences in oral hygiene habits were revealed among those groups.

The main finding of the study was that sleep disorders and fatigue were associated with poor oral health-related behavior, while no association with stress was revealed. In September regular napping and negative opinion towards self-reported sleep quality were associated with insufficient use of auxiliary dental hygiene appliances: dental floss and tongue cleaner. In September sleep disturbances were more prevalent than stress or fatigue. Considering the fact that in September dental students were well rested after a 3-month long summer break and had a minimum amount of university related assignments, it is likely that sleep disturbances and consequently insufficient oral health habits were influenced by poor sleep hygiene $32.6 \%$ took naps daily or every other day, $75.1 \%$ went to sleep at midnight or later during working days while during weekends $65.2 \%$ went to sleep at 1 am or later. Similar results regarding university students' poor sleep hygiene knowledge and habits can be found in other studies. ${ }^{21}$ Assessing changes in December poor oral health-related behavior were associated with sleep disturbances as well as fatigue. A nearly 3-fold increase in the prevalence of insomnia correlated with declined use of a toothbrush. This data lacks any directly comparable findings in previous studies, but it is known that persistent insomnia increases the risk of depression. ${ }^{22}$ An association between depression and oral health status or oral health-related behavior has been revealed in previous studies. ${ }^{23-25}$ Our study did not aim to investigate symptoms of depression, even though it is likely that some students might be experiencing those symptoms, as depression is a comorbid disease with insomnia, stress and fatigue.

The present study supports the findings of Dumitres$\mathrm{cu}$ et al. whose study revealed that fatigue was related to poor oral hygiene habits. ${ }^{4}$ However, this correlation was revealed only during the examination period. It is likely that fatigue is a consequence of long lasting sleep disturbances and stress, heavy workload and no recent vaca- tion. Some of the mentioned factors were not present in September; therefore, the prevalence of fatigue was significantly lower and had no influence on the oral hygiene habits at the beginning of the academic year.

Another important finding was that stress did not correlate with oral health-related behavior among dental students. Research suggests that chronic stress is associated with deregulation of the neuroendocrine and sympathetic nervous systems causing changes in the immune system and consequently resulting in an increased risk of periodontal diseases, recurrent aphthous ulcerations, herpes virus infections, etc. ${ }^{26}$ Moreover, it is known that chronic stress can mediate the risk of periodontitis through changes in healthrelated behavior, such as oral hygiene, diet and smoking. ${ }^{27,28}$ There could be several explanations why the current study failed to find an association between oral hygiene and stress. First of all, our study did not aim to distinguish short-term stress from chronic stress. It is likely that students experienced short-lived stress related to the examination period. Short-term stress, as opposed to chronic stress, has a stimulating effect, possibly resulting in unchanged oral healthrelated behavior. Secondly, stress is often associated with perfectionist personality type ${ }^{29}$ A perfectionist person, especially in the field of dental studies, is self-conscious about personal oral health status and, therefore, such a person is likely to have sufficient oral hygiene habits.

It is important to point out that the dropout rate of the present study was $8.9 \%$. Nine dental students, who filled in the questionnaire in September, did not complete it the second time in December. Since the questionnaire was distributed during the lectures, only students who did not attend did not complete the form. In order to raise the response rate, an electronic questionnaire form was put on the Internet. It is likely that lecture truancy is a consequence of fatigue, stress or sleep disturbances. Therefore, 9 students who dropped out of the study probably would not have had a significant impact on the findings of the study.

Study revealed that oral health-related behavior worsen during examination period when higher prevalence of stress, fatigue and sleep disturbances are observed.

\section{References}

1. Dumitrescu AL, Toma C, Lascu V. Relationship of humour with oral health status and behaviours. Rom J Intern Med. 2010;48:333-339.

2. Dumitrescu AL, Toma C, Lascu V. Self-liking, self-competence, body investment and perfectionism: Associations with oral health status and oral-health-related behaviours. Oral Health Prev Dent. 2009;7:191-200. 
3. Dumitrescu AL, Dogaru CB, Dogaru CD. Instability of self-esteem and affective lability as determinants of self-reported oral health status and oral health-related behaviors. J Contemp Dent Pract. 2008;9:38-45.

4. Dumitrescu AL, Toma C, Lascu V. Associations among sleep disturbance, vitality, fatigue and oral health. Oral Health Prev Dent. 2010;8:323-330.

5. Sato M, Camino J, Oyakawa HR, et al. Effect of dental education on Peruvian dental students' oral health-related attitudes and behavior. J Dent Educ. 2013;77:1179-1184.

6. Lang NP, Cumming BR, Löe HA. Oral hygiene and gingival health in Danish dental students and faculty. Community Dent Oral Epidemiol. 1977;5:237-242.

7. Wheatley D. Stress, anxiety and depression. Stress Med. 1997;13:173-177.

8. Alzahem AM, van der Molen HT, Alaujan AH, Schmidt HG, Zamakhshary MH. Stress amongst dental students: A systematic review. Eur J Dent Educ. 2011;15:8-18.

9. Maurice $M$, Ohayon M. Epidemiology of insomnia: What we know and what we still need to learn. Sleep Med Rev. 2002;6:97-111.

10. Robaina JR, Lopes CS, Rotenberg L. Epidemiology of insomnia: prevalence and risk factors, can't sleep? Issues of being an insomniac, Dr. Saddichha Sahoo (Ed.), 2012, DOI: 10.5772/32991.

11. Dahlgren A, Kecklund G, Åkerstedt T. Different levels of work-related stress and the effects on sleep, fatigue and cortisol. Scand J Work Environ Health. 2005;31:277-285.

12. Holmes GP, Kaplan JE, Gantz NM, et al. Chronic fatigue syndrome: A working case definition. Ann Intern Med. 1988;108:387-389.

13. Weber A, Jaekel-Reinhard A. Burnout syndrome: A disease of modern societies? Occup Med (Lond). 2000;50:512-517.

14. Michielsen HJ, De Vries J, Van Heck GL. Psychometric qualities of a brief self-rated fatigue measure: The Fatigue Assessment Scale. J Psychosom Res. 2003;54:345-352.

15. Kecklund G, Åkerstedt T. The psychometric properties of the Karolinska Sleep Questionnaire. J Sleep Res. 1992;1:113.

16. Reeder LG, Chapman JM, Coulson AH. Socioenvironmental stress, tranquilizers and cardiovascular disease. Proceedings of the Excerpta Medica International Congress Series. 1968;182:226-238.

17. De Vries J, Michielsen HJ, Van Heck GL. Assessment of fatigue among working people: A comparison of six questionnaires. Occup Environ Med. 2003;60:i10-i15.

18. De Vries J, Michielsen HJ, Van Heck GL, Drent M. Measuring fatigue in sarcoidosis: The fatigue assessment scale (FAS). Br J Health Psychol. 2004;9:279-291.

19. Goštautas A. Psichologiniai streso aspektai. Sveikata. 1999;6:55-58.

20. Dahlin M, Joneborg N, Runeson B. Stress and depression among medical students: A cross-sectional study. Med Educ. 2005, 39:594-604.

21. Suen LK, Tam WW, Hon KL. Association of sleep hygiene-related factors and sleep quality among university students in Hong Kong. Hong Kong Med J. 2010;16:180-185.

22. Liqing L, Chunmei W, Yong G, Xianguo Q, Zuxun L. Insomnia and the risk of depression: A meta-analysis of prospective cohort studies. BMC Psychiatry. 2016;16:375.

23. Klages $\mathrm{U}$, Weber AG, Wehrbein $\mathrm{H}$. Approximal plaque and gingival sulcus bleeding in routine dental care patients: Relations to life stress, somatization and depression. J Clin Periodontol. 2005;32:575-582.

24. Okoro CA, Strine TW, Eke PI, Dhingra SS, Balluz LS. The association between depression and anxiety and use of oral health services and tooth loss. Community Dent Oral Epidemiol. 2012;40:133-144.

25. Baglioni C, Battagliese G, Feige B, Spiegelhalder K, Nissen C, Voderholzer U. Insomnia as a predictor of depression: A meta-analytic evaluation of longitudinal epidemiological studies. J Affect Disord. 2011:135:10-19.

26. Kimberly RW, Teodor TP, Maureen EG, Omar P, Deanna LK, Mark AR. Role of chronic stress and depression in periodontal diseases. Periodontol 2000. 2014;64:127-138.

27. Aleksejuniene J, Holst D, Eriksen HM, Gjermo P. Psychosocial stress, lifestyle and periodontal health. J Clin Periodontol. 2002;29:326-335.

28. Ravishankar TL, Ain TS, Gowhar O. Effect of academic stress on plaque and gingival health among dental students of Moradabad, India. J Periodontol. 2014;16:115-120.

29. Luyten P, Kempke S, Van Wambeke P, Claes S, Blatt SJ, Van B. Selfcritical perfectionism, stress generation, and stress sensitivity in patients with chronic fatigue syndrome: relationship with severity of depression. Psychiatry. 2011;74:21-30. 